\title{
Coarctation of aorta aneurysm with aberrant right subclavian artery and single carotid artery: Surgical and perfusion strategies
}

Balasubramoniam Kavumkal Rajagopalan, $\mathrm{MCh},{ }^{\mathrm{a}}$ Rajesh Jose, $\mathrm{MCh},{ }^{\mathrm{a}}$ Nazar Puthukudiyil Kader, MD, and Praveen Kerala Varma, $\mathrm{MCh},{ }^{\mathrm{a}}$ Kochi, India

\footnotetext{
From the Departments of ${ }^{\mathrm{a}}$ Cardiovascular and Thoracic surgery and ${ }^{\mathrm{b}}$ Radio Diagnosis, Amrita Institute of Medical Sciences, Amrita Viswa Vidyapeetham (Amrita University), Kochi, Kerala, India.

Disclosures: Authors have nothing to disclose with regard to commercial support.

Received for publication April 26, 2018; revisions received June 24, 2018; accepted for publication Aug 26, 2018 available ahead of print Oct 29, 2018.

Address for reprints: Balasubramoniam Kavumkal Rajagopalan, MCh, Department of Cardiovascular and Thoracic Surgery, Amrita Institute of Medical Sciences, Amrita Viswa Vidyapeetham (Amrita University), Kochi, Kerala, India (E-mail: drbala21101@gmail.com).

J Thorac Cardiovasc Surg 2019;157:e17-9

$0022-5223 / \$ 36.00$

Copyright (c) 2018 Published by Elsevier Inc. on behalf of The American Association for Thoracic Surgery https://doi.org/10.1016/j.jtcvs.2018.08.108
}

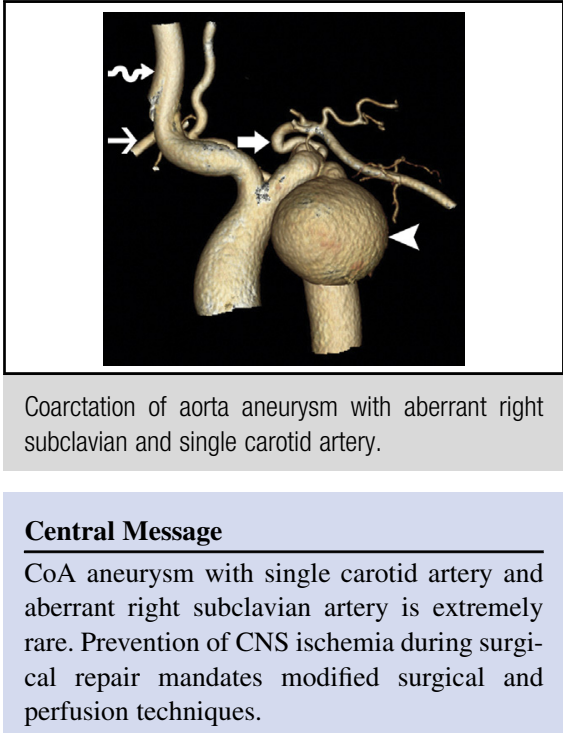

See Editorial Commentary page e21.
Coarctation of aorta aneurysm with aberrant right subclavian artery and single carotid artery is a rare and complex congenital aortic anomaly. We present the surgical and perfusion strategy that we used to maintain cerebral and spinal cord perfusion during repair, thereby preventing devastating complications of stroke and paraplegia. Written patient consent was obtained for this case report.

\section{CLINICAL SUMMARY}

A 28-year-old female patient presented with dyspnea on exertion, New York Heart Association functional class II, 6 months in duration. Contrast computed tomographic aortogram (Figure 1 and Video 1) showed a $5.2 \times 4.7-\mathrm{cm}$ saccular aneurysm arising from the coarctation segment. The left subclavian artery originated just distal to the aneurysm, and the aberrant right subclavian artery originated posteroinferiorly, $2.5 \mathrm{~cm}$ below the coarctation. The left common carotid artery was absent, and the right common carotid artery origin was directly from the arch of the aorta. The right vertebral artery was dominant, whereas the left was hypoplastic. No intracerebral aneurysms were detected. On Doppler study, the dominant right vertebral artery showed reversal of flow and represented the single large collateral to the lower part of body through the aberrant right subclavian artery. Transthoracic echocardiography showed a normally functioning bicuspid aortic valve. There was a gradient of $82 \mathrm{~mm} \mathrm{Hg}$ across the coarctation. Close proximity $(1 \mathrm{~cm})$ of the precious single carotid artery to the saccular aneurysm precluded an endovascular strategy in our case.

Prosthetic graft replacement of the coarctation segment and reimplantation of the left subclavian artery with ligation of the aberrant right subclavian artery was the surgical plan. The left lung was isolated, and the thoracoabdominal position was used with initiation of femorofemoral cardiopulmonary bypass. A fourth-space left posterolateral thoracotomy was performed, followed by main pulmonary artery cannulation for improved venous return. The ascending aorta was cannulated from left thoracotomy, and 2 pump heads ( 1 for the upper body and 1 for the lower body) were used for arterial return. A lower body-upper body perfusion ratio of 2:1 was maintained. Left radial and femoral artery pressures were maintained at mean of $50 \mathrm{~mm} \mathrm{Hg}$. Cerebral oximetry was used to ensure adequacy of cerebral perfusion. Total circulatory arrest was attained at $18^{\circ} \mathrm{C}$. An 18-mm Dacron polyester fabric graft (Terumo Aortic, Inchinnan, United Kingdom) was used to replace the affected aortic segment. Proximal anastomosis was done immediately distal to ostia of the single carotid artery, 


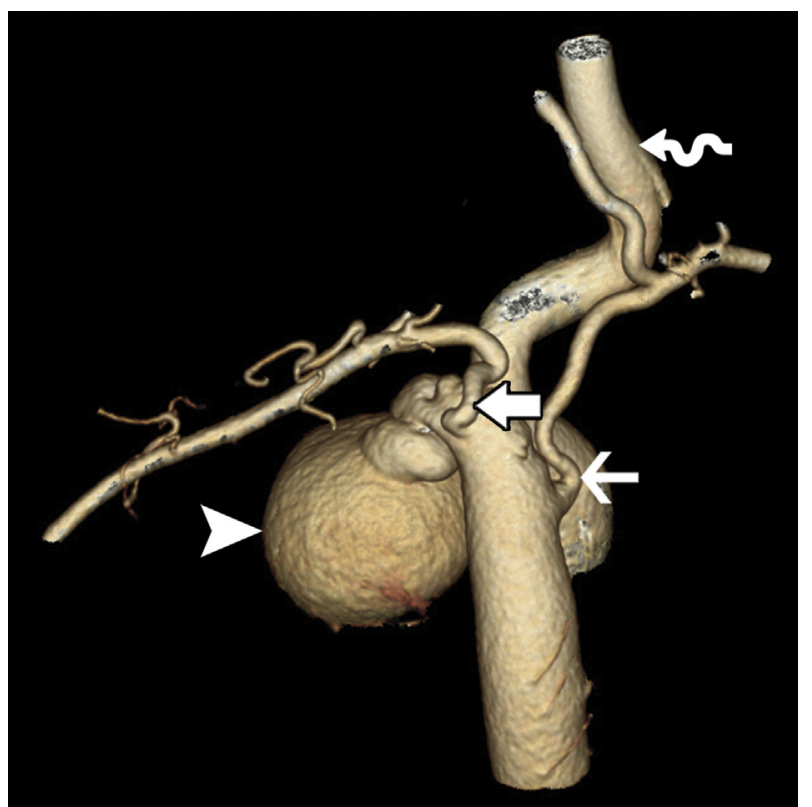

FIGURE 1. Posterior view shows coarctation of aorta saccular aneurysm (arrowhead), aberrant right subclavian artery (thin arrow), single carotid artery (curved arrow), and left subclavian artery (thick arrow).

with a circulatory arrest time of 31 minutes. Selective upper body perfusion was started after the graft was clamped. Distal anastomosis to proximal descending thoracic aorta was performed after ligation of the aberrant subclavian artery. The left subclavian artery was reimplanted onto the aortic prosthetic graft (Figure 2 and Video 2). Total cardiopulmonary bypass time was 261 minutes. The patient recovered well, without stroke or paraplegia, and was discharged uneventfully.

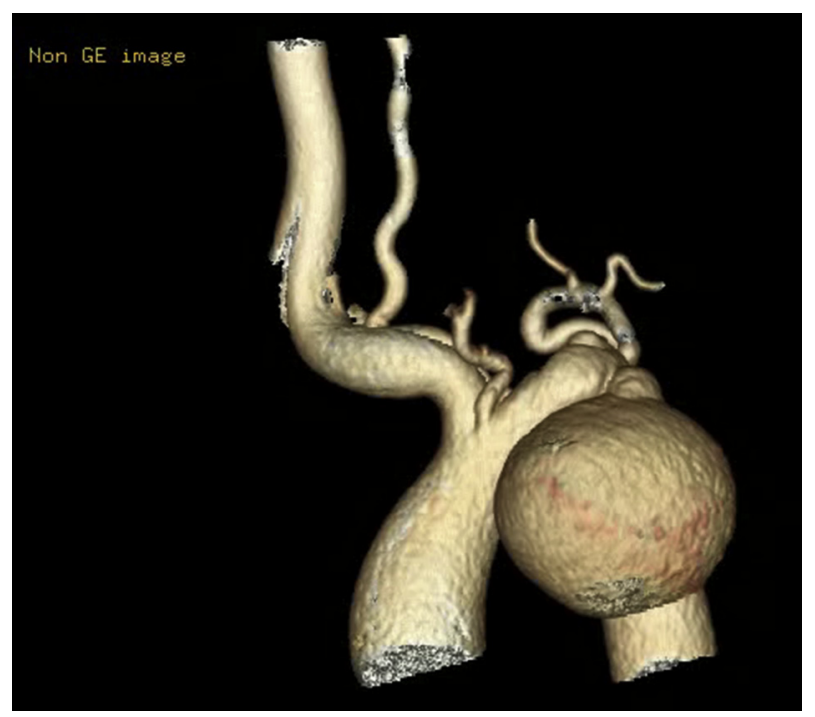

VIDEO 1. Preoperative 3-dimensional rotational computed tomographic reconstruction. Video available at: https://www.jtcvs.org/article/S00225223(18)32503-0/fulltext.

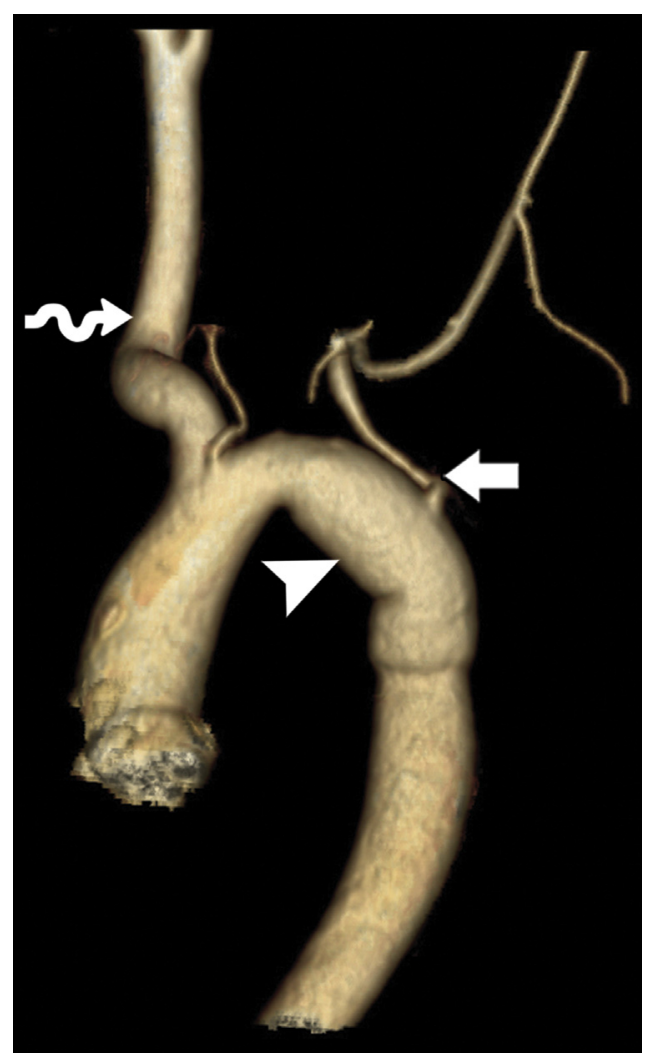

FIGURE 2. View after repair shows Dacron polyester fabric graft (arrowhead), left subclavian artery reimplanted onto aortic graft (thick arrow), and single carotid artery (curved arrow).

\section{DISCUSSION}

Coarctation of aorta occurs in 3.2 of 10,000 births. It is isolated in $82 \%$ of cases and is associated with an aberrant right subclavian artery in $1 \% .{ }^{1}$ In our case, coarctation of aorta aneurysm with aberrant right subclavian artery and single carotid artery significantly increased the intraoperative risks of cerebral and spinal cord ischemia. We were unable to find a similar presentation in literature.

Embryologically, the proximal segment of the right subclavian artery is derived from the right fourth arch, the middle segment is derived from cranial portion of the right dorsal aorta, and the distal segment is derived from the right seventh intersegmental artery. The right dorsal aorta normally disappears between the origin of seventh intersegmental artery and the junction with the left dorsal aorta. Persistence of right dorsal aorta and disappearance of right fourth arch and the cranial portion of the right dorsal aorta results in an aberrant right subclavian artery. ${ }^{2}$ Abnormal involution of the left third aortic arch results in absent left carotid artery.

Collateral circulation in coarctation of the aorta was described by Abbot. ${ }^{3}$ Spinal cord circulation depends on the anterior spinal artery reinforced in $\mathrm{C} 1$ to $\mathrm{T} 2$ segment by branches of the subclavian arteries. ${ }^{4}$ An aberrant right 


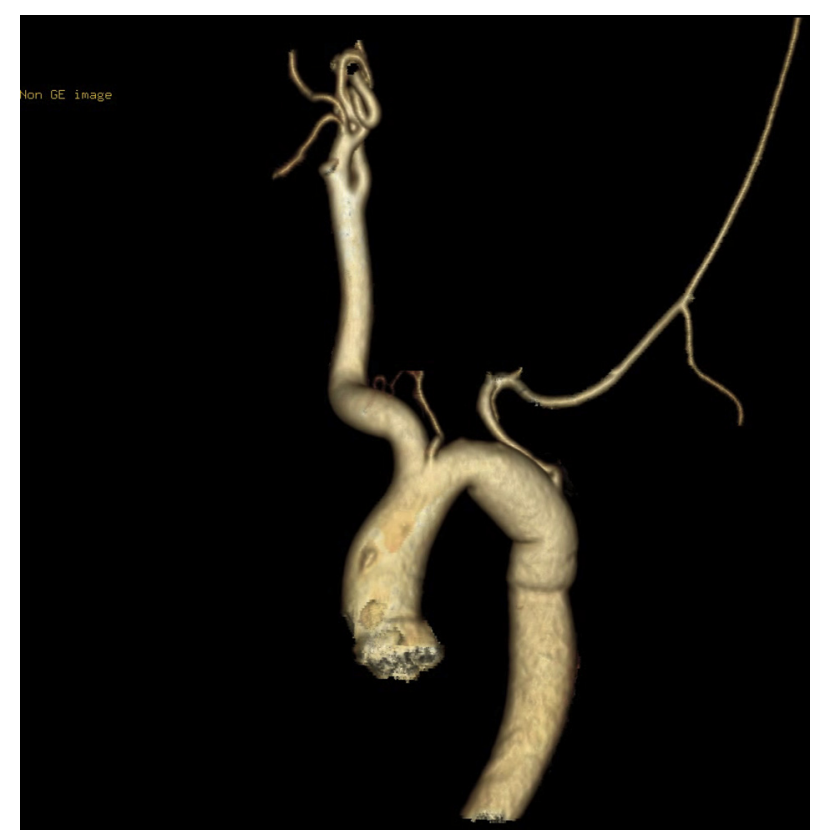

VIDEO 2. Postoperative 3-dimensional rotational computed tomographic reconstruction. Video available at: https://www.jtcvs.org/article/S00225223(18)32503-0/fulltext.

subclavian artery formed the only descending aortic collateral in our patient, thus increasing the risk of intraoperative spinal cord ischemia. Femorofemoral bypass alone did not guarantee adequate retrograde cerebral perfusion across the coarctation segment with gradient of $82 \mathrm{~mm}$. The ascending aorta was cannulated to provide antegrade cerebral perfusion. Carotid artery cannulation was avoided, because any untoward injury to this artery would be disastrous in this case. An open technique of anastomosis under total cardiac arrest was used to locate the proximal anastomosis precisely, immediately distal to the carotid ostia. On proximal anastomosis completion, the graft and the distal aorta were clamped, and proximal and distal perfusion was restarted at a ratio of 1:2. This strategy protects the ischemic watershed zone $\mathrm{T} 2$ to $\mathrm{T} 7$ of the spinal cord, in addition to supplying the artery of Adamkeiwcz. ${ }^{4}$

\section{References}

1. Denton OJ, Bloor J, Martin RP, Tometzki AJ, Hamilton MC, Smith FC. Anomalous right subclavian artery and coarctation related aneurysm repaired with bilateral subclavian-to-carotid transposition and exclusion stent-grafting. Eur J Vasc Endovasc Surg. 2008;36:300-2.

2. Odell JA, Spilkin S. Anomalous right subclavian artery and coarctation of the aorta. Surgical implications and the use of the right subclavian artery as a flap. Br Heart J. 1984:51:666-9.

3. Abbott ME. A statistical study and historical retrospect of 200 recorded cases, with autopsy, of stenosis OR obliteration of the descending arch in the subjects above the age of two years. Am Heart J. 1928;3:381-421.

4. Hjortdal VE, Khambadkone S, de Leval MR, Tsang VT. Implications of anomalous right subclavian artery in the repair of neonatal aortic coarctation. Ann Thorac Surg. 2003;76:572-5. 